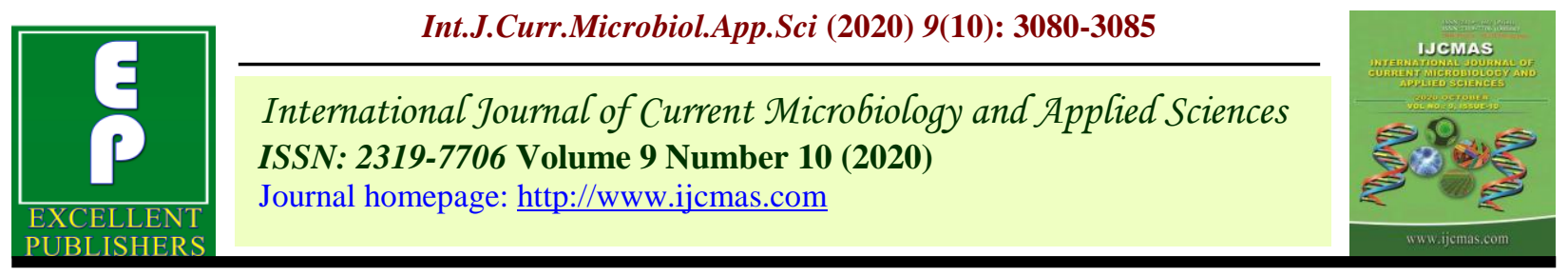

Case Study

https://doi.org/10.20546/ijcmas.2020.910.370

\title{
Fatty Liver Haemorrhagic Syndrome in Layers
}

\author{
S. Soujanya ${ }^{1 *}$, M. Lakshman ${ }^{2}$ and D. Madhuri ${ }^{1}$ \\ ${ }^{1}$ Department of Veterinary Pathology, College of Veterinary Science, Korutla, \\ PVNRTVU, Hyderabad, India \\ ${ }^{2}$ Departmentof Veterinary Pathology, College of Veterinary Science, Rajendranagar, \\ PVNRTVU, Hyderabad, India \\ *Corresponding author
}

\section{A B S T R A C T}

\section{Keywords}

FLHS, Layers,

Liver rupture,

Vacuoles, H\&E

staining

Article Info

Accepted:

24 September 2020

Available Online:

10 October 2020
In layers, Fatty liver haemorrhagic syndrome (FLHS) is one of the common metabolic disorder which results in mortality. FLHS was diagnosed in layers of a commercial farm by postmortem examination and microscopic lesions in liver. The clinical signs like depression, decrease in egg production, pale coombs and wattles and sudden death were noticed. Postmortem examination of the dead birds revealed enlarged, yellowish, friable and greasy liver with haemorrahic streaks. In few birds, liver was ruptured, and large blood clots were observed in thoracic and abdominal cavity. Abundant fatty deposits were also seen in abdominal cavity. Microscopically, liver sections showed small clear vacuoles in hepatocytes with Haematoxylin and eosin (H\&E) staining.

\section{Introduction}

Fatty liver haemorrhagic syndrome (FLHS) is a metabolic disease of mostly caged layers fed on high energy diets and characterized by reduced egg production, increased accumulation of fat in the liver, rupture of liver, internal bleeding and sudden death (Butler, 1976; Crespo and Shivaprasad, 2008; Lee et al., 2010; Jiang et al., 2013; Rozenboim et al., 2016). It is mostly seen in caged birds but in USA, FLHS was also reported in free-range backyard poultry (Trott et al., 2014).In one of the studies in Queensland, $74 \%$ of the mortality was reported in caged layers due to FLHS (Shini, 2014).FLHS is a multifactorial disease and is produced by various factors like nutritional, environmental, genetical, hormonal and metabolic factors. Nutritional factor such as excessive consumption of high energy diet has been strongly associated with the occurrence of this condition and huge amount of fat deposits were found in $97 \%$ of the 
affected birds (Trott et al., 2014). High environmental temperature has also been reported to play a key role to cause this condition (Pearson et al., 1981). Genetical factor such as strain predisposition to FLHS has been studied by some researchers (Thomson et al., 2003; Yeh et al., 2009). In FLHS, the haemorrhage may result from the destruction of the hepatic reticulin fibers and capsule due to vacuolar swelling of the hepatocytes with accumulation of fat (Hansen and Walzem, 1993) and also due to oxygen derived free radicals (Spurlock and Savage, 1993). Supplementation of diet rich in antioxidants reduces the incidence of FLHS (Spurlock and Savage, 1993). The present study describes the characteristic gross and microscopic changes in liver of FLHS affected layers in a commercial farm.

\section{Materials and Methods}

In a layer farm, the history of clinical signs shown by the sick birds was collected and postmortem examination of the dead birds was performed as per the standard procedure. Gross lesions were recorded, and liver slices were collected in $10 \%$ neutral buffered formalin (NBF) for histopathological examination. After fixation in NBF, the tissue was washed under running tap water for overnight, then dehydrated in ascending grades of alcohol, cleared in xylene, embedded in liquid paraffin and then blocks were made. By using microtome, $5 \mu \mathrm{m}$ thin sections were cut from paraffin blocks and then sections were stained with haematoxylin and eosin as per the standard protocol ((Luna, 1968).

\section{Results and Discussion}

\section{Clinical signs}

The sick birds showed depression, dullness, decrease in egg production, pale coombs and wattles and sudden death

\section{Gross lesions}

On necropsy, the liver was moderately enlarged, pale to yellowish in color, fragile, greasy in consistency and hemorrhagic streaks were noticed on the surface (Fig. 1). In few birds, ruptured liver with blood clots in the thoracic and abdominal cavity were observed and abundant intracelomic fat was noticed (Fig. 2).

\section{Histopathology}

Microscopic section of liver revealed distended hepatocytes with small clear vacuoles in the cytoplasm which displaced the nucleus to periphery (Fig. 3 and 4).

Fig.1 Layer bird showing swollen, pale, friable liver with hemorrhagic streaks on the surface and abundant intracelomic fat in FLHS

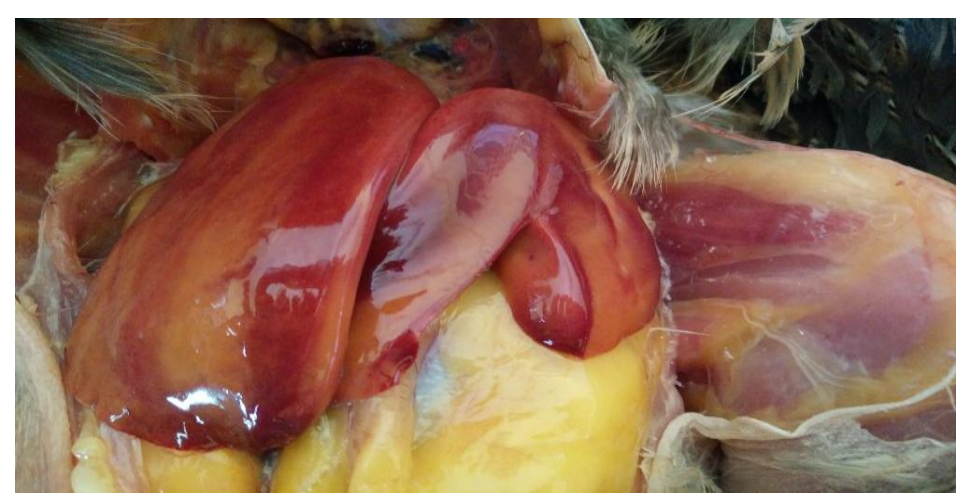


Fig.2 Layer bird showing enlarged, pale, ruptured liver with blood clots in the thoracic and abdominal cavity and abundant intracelomic fat in FLHS

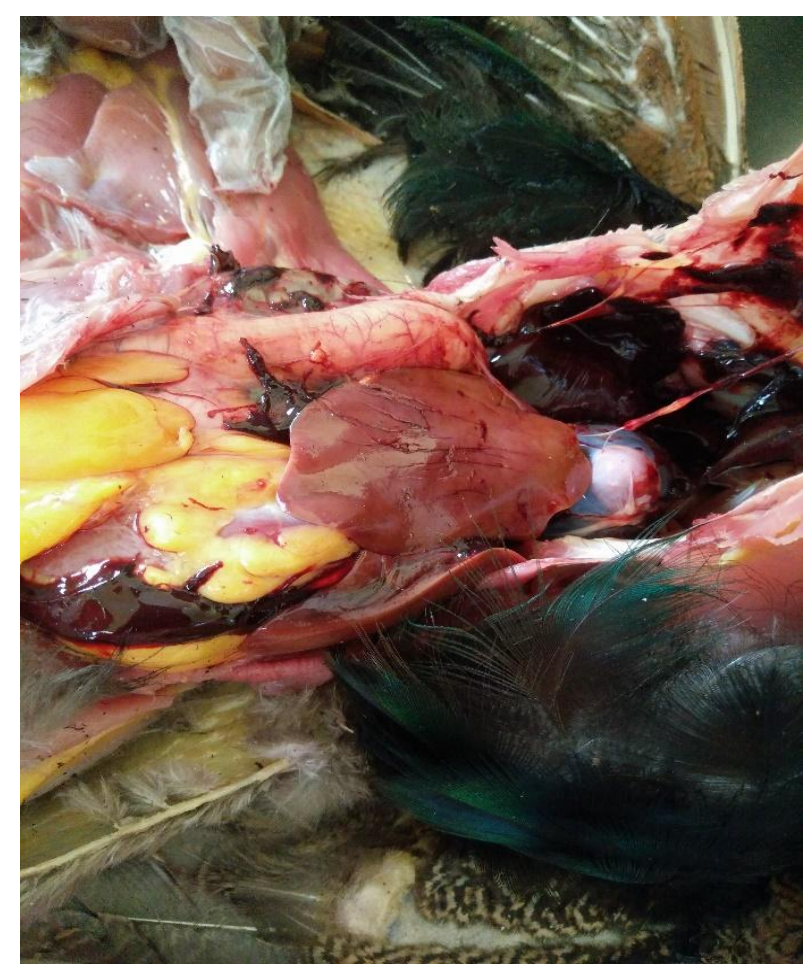

Fig.3 Liver section showing small clear vacuoles in hepatocytes in FLHS (H\&E x 20)

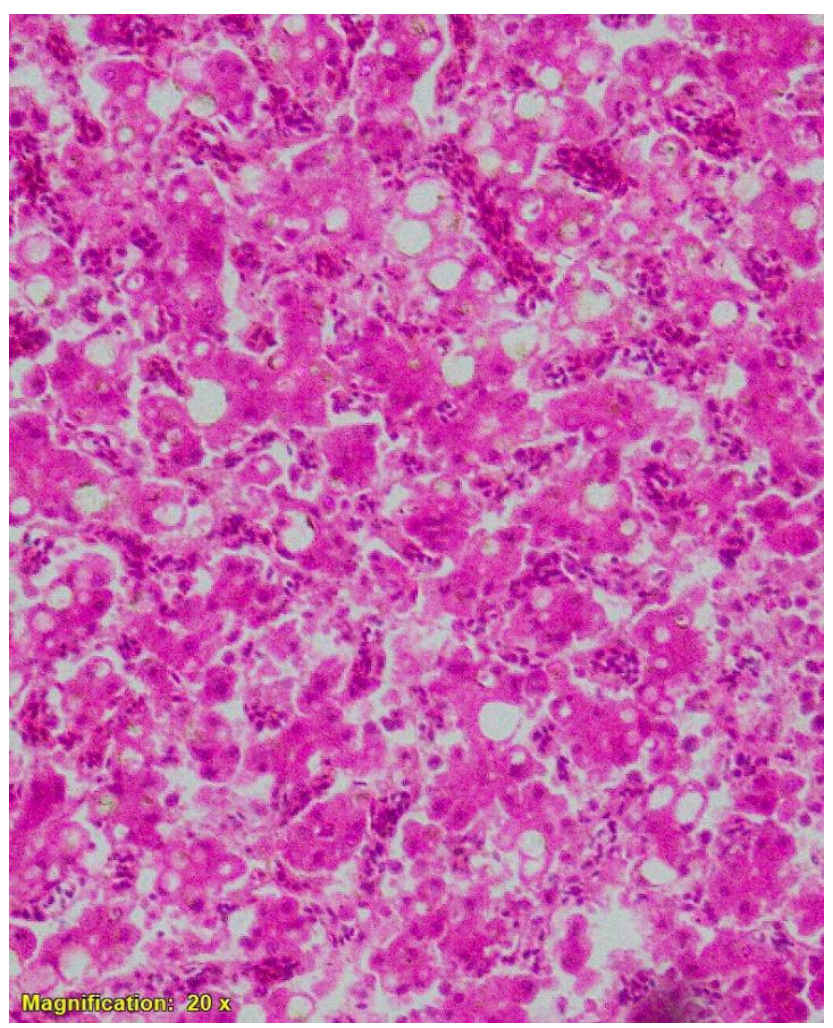


Fig.4 Liver section showing small clear vacuoles in hepatocytes in FLHS (H\&E x 10)

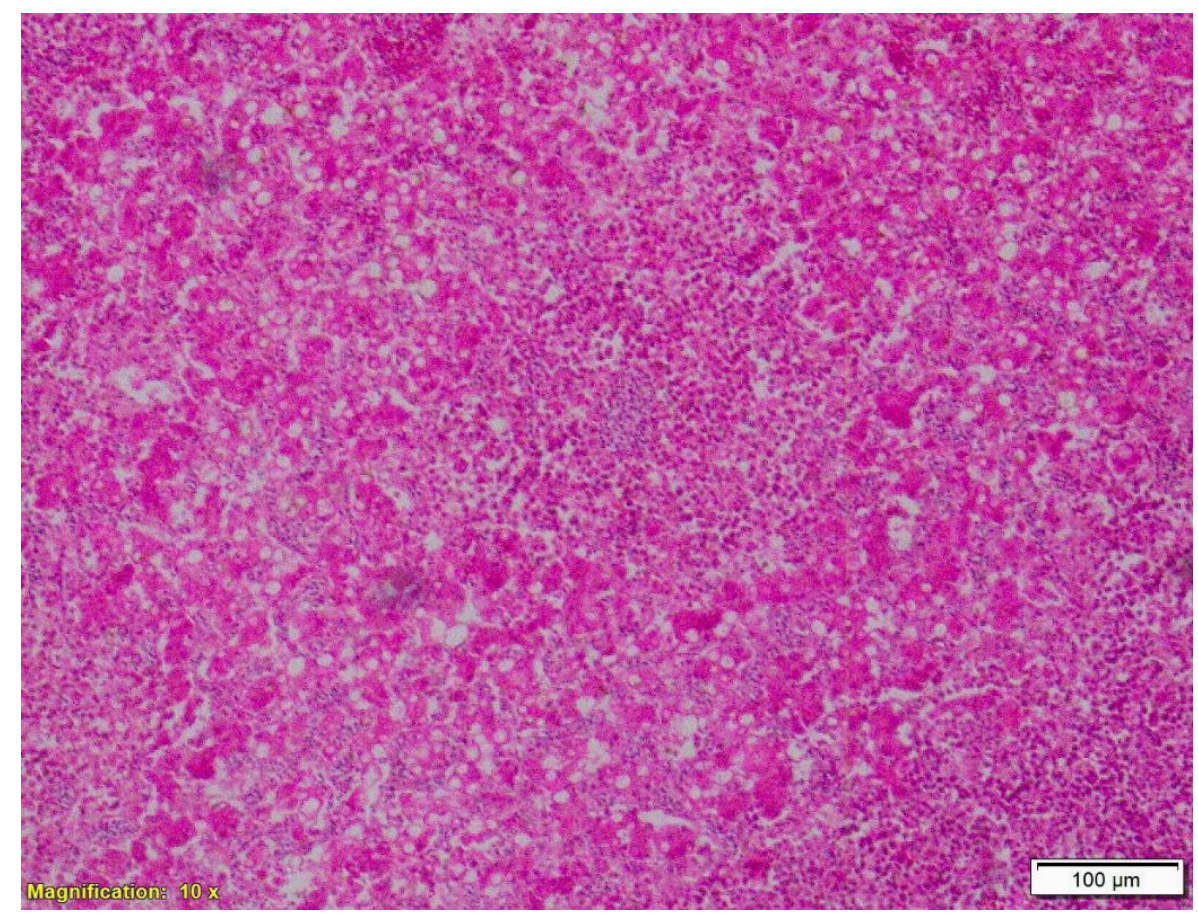

In present study, gross lesions noticed in FLHS affected layers included enlargement, pale to yellowish discoloration, friable, greasy consistency of the liver with hemorrhagic streaks on the surface, liver rupture, blood clots in the thoracic and abdominal cavity and abundant intracelomic fat. Microscopically, liver sections showed small clear fat vacuoles in the cytoplasm of hepatocytes. Similar gross and histopathological lesions were earlier reported by some researchers (Wadsworth et al., 1984; Trott et al., 2014; Dey et al., 2018; Sandaand Ezeifeka, 2019).

FLHS in commercial layer farms may be predisposed by high energy diet, overcrowding, high environmental temperature and cage system (Tablante et al., 1994). In present study, the FLHS might have precipitated by cage system management, high temperature and high energy diet. Similarly, previous studies also reported that the occurrence of FLHS is high in caged birds (Shini, 2014), in higher ambient temperature (Reddy et al., 1995)and also due to feeding of high fat diets (Rozenboim et al., 2016). In current study, the FLHS was seen in birds that are in active stage of laying which indicates that there is a hormonal involvement in the occurrence of this disorder (Dey et al., 2018).By providing low energy and high protein diet, antioxidant vitamin supplements and by maintaining the environmental temperature the incidence of FLHS can be reduced.

In conclusion, the current study revealed that FLHS can be diagnosed based on gross and microscopic lesions in liver. The FLHS may be precipitated by multiple factors like cage system management, high dietary energy, high temperature and hormonal imbalance and hence all these factors need to be considered for its effective control and for prevention of economical loss to the farmer.

\section{Acknowledgements}

The Authors are thankful to the College of Veterinary Science, PVNRTVU, 
Rajendranagar, Hyderabad for providing the facilities to carry out the present research work.

\section{References}

Butler, E.J. 1976. Fatty liver diseases in the domestic fowl. A review. Avian Pathol. $5: 114$.

Crespo, R. and Shivaprasad, H.L.2008. Developmental, metabolic, and other noninfectious disorders, In: Diseases of Poultry, 12 ed., Chap.30, Blackwell Publishing Limited, United Kingdom, pp. 1173-1174.

Dey, S., Pakhira, M.C., Batabyal, K., Isore, D.P. and Samanta, I. 2018. Concurrent occurrence of fatty liver haemorrhagic syndrome (FLHS) and colisepticaemia in a broiler breeder flock. Int. J. Curr. Microbiol. App. Sci., 7(9): 185-189.

Hansen, R. J., and R. L. Walzem. 1993. Avian fatty liver hemorrhagic syndrome: a comparative review. Adv. Vet. Sci. Comp. Med., 37: 451-468.

Jiang, S., Cheng, H.W., Cui, L.Y., Zhou, Z.L. and Hou, J.F. 2013. Changes of blood parameters associated with bone remodeling following experimentally induced fatty liver disorder in laying hens. Poult. Sci., 92: 1443-1453.

Lee, B.K., Kim, J.S., Ahn, H.J., Hwang, J.H., Kim, J.M., Lee, H.T., An, B.K. and Kang, C.W. 2010. Changes in hepatic lipid parameters and hepatic messenger ribonucleic acid expression following estradiol administration in laying hens (Gallus domesticus). Poult. Sci., 89: 2660-2667.

Luna, G.L.H.T. 1968. Manual of Histological and Special Staining Techniques, 2nd Edition: 1-5 and 9-34.

Pearson, A.W., Curtis, M.J. and Butler, E.J., 1981. Bacterial endotoxins and the pathogenesis of fatty liver haemorrhagic syndrome in the laying hen. Res. Vet.
Sci., 31: 259-261.

Reddy, K.P., Sivaramakrishna B. and Radhakrishniah, K. 1995. Incidence of fatty liver haemorrhagic syndrome in broiler chicken. Poult. Adviser., 28(4): 21-23.

Rozenboim, I., Mahato, J., Cohen, N.A. and Tirosh, O. 2016. Low protein and high energy diet: a possible natural cause of fatty liver hemorrhagic syndrome in caged White Leghorn laying hens. Poult. Sci., 95:612-621.

Sanda M.E. and Ezeifeka A.C.2019. Fatty liver haemorrhagic syndrome (FLHS) in laying birds: a case report. Int. J. Agric. Vet. Sci., 5(1):4-12.

Shini, A. 2014. Fatty Liver Haemorrhagic Syndrome in Laying Hens: Field and Experimental Investigations. PhD Thesis, School of Agriculture and Food Sciences, The University of Queensland, Australia.

Spurlock, M.E. and Savage, J.E. 1993. Effect of dietary protein and selected antioxidants on fatty liver hemorrhagic syndrome induced in Japanese quail. Poult. Sci., 72: 2095-2105.

Tablante, N.L., Vaillancourt, J.P. and Julian, R.J. 1994. Necrotic, haemorrhagic, hepatomegalic hepatitis associated with vasculitis and amyloidosis in commercial laying hens. Avian Pathol., 23:725-732.

Thomson, A.E., Gentry,P.A. and Squires, E.J. 2003. Comparison of the coagulation profile of fatty liver haemorrhagic syndrome susceptible laying hens and normal laying hens. Br.Poult. Sci., 44: 626-633.

Trott, K.A., Giannitti, F., Rimoldi, G., Hill, A., Woods, L., Barr, B., Anderson, M., and Mete, A.2014. Fatty liver hemorrhagic syndrome in the backyard chicken: A retrospective histopathologic case series. Vet. Pathol., 51(4): 787795. 
Wadsworth, P.F., Jones D.M. and Pugsley S.L. 1984. Fatty liver in birds at the zoological society of London, Avian Pathol., 13(2): 231-239.

Yeh, E., Wood, R.D., Leeson, S. et al., 2009. Effect of dietary omega-3 and omega- 6 fatty acids on clotting activities of Factor V, VII and $\mathrm{X}$ in fatty liver haemorrhagic syndrome susceptible laying hens. Br. Poult. Sci., 50: 382392.

\section{How to cite this article:}

Soujanya, S., M. Lakshman and Madhuri, D. 2020. Fatty Liver Haemorrhagic Syndrome in Layers. Int.J.Curr.Microbiol.App.Sci. 9(10): 3080-3085.

doi: https://doi.org/10.20546/ijcmas.2020.910.370 